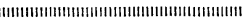

資料

TECHNICAL NOTE

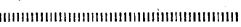

炭素鋼配管内面に生じた孔食深さの統計的性質 ${ }^{\dagger}$

正村 克 身* 松 島 宸**

\title{
Statistical Characteristics of Pit Depth Observed on Inner Surface of Carbon Steel Pipes
}

by

Katsumi Masamura* and Iwao Matsushima**

\begin{abstract}
Statistical characteristics of pitting corrosion observed under tubacular on carbon steel used for fresh water pipes are discussed. Thirty three cases were analysed using the statistical method. The Gausian distribution was applied for the distribution of pit depth in carbon steel. The mean and standard deviation of pit depth had no dependence on duration of use in practice. The standard deviation of pit depth rather than the mean is a good indicator for the estimation of potential occurrence of penetration. The index, $m+3 \sigma$, is a good indicator for the occurrence of perforation. The standard deviation and mean of pit depth showed good correlation. It is difficult to estimate the life time of pipes using statistical analysis of pit depth because the law of pit growth is unclear. キー・ワード : 炭素鋼, 孔食, 統計的性質
\end{abstract}

\section{1 緒言}

近年，腐食現象の統計的な性質に対する関心が高ま り，種々の報告が行われている．特に，極値統計を石 油タンクの底板やスラリーパイプラインの内面に生じ た孔食の最大深さの推定に適用して, 装置の損傷状況 を把握することに成功した事例がいくつか報告されて いる. 現在，極值統計などの統計的手法を応用して， 两る時点における損傷状沉を評価することは充分可能 である。このような取り扱いを行ら上で実装置におい て孔食深さにどのよらな分布型にあてはめられるかな ぞの腐食現象の統計的性質を明らかにすることは, 少 ないデータで有効な情報を得るために重要である。

一方，装置の残存寿命を予測するためには，孔食な ぞの腐食現象の進行速度に関する速度則が必要である. 石川らは実働機器における局部腐食へ極值統計を系統 的に適用して, 各種パラメータの時間依存性を明らか にしている. 本田らもスラリ一配管に生じた孔食深さ の解析の中で最大孔食深さの極值分布の時間依存性を 調べ，配管の寿命を予測している. しかし，現在のと ころこのような事例はまだ少なく，任意の装置の腐食 状況を調べて寿命を予測することはできない。

著者らは，ごれまでに多数の淡水配管の腐食事例を 扱い，さびこぶ下に生じた孔食の深さを測定した。 こ れらのデータを解析して，炭素鋼に生じるさびこぶ下 の孔食の統計的な性質を調べた結果を報告する。あわ
せて, 寿命予測飞必要な孔食の進行速度の速度則を明 らかにするために必要な考觉かたを示す。

\section{2 孔食深さの測定と分布}

Table I に今回扱った事例16件（サンプル33本）の 一覧を示す，使用環境は淡水に限定し，給水管，冷却 循環水配管および温水配管である。これらの事例にお ける主な腐食は，さびこぶ下に生じた孔食と電縫鋼管 の溶接部に生じた溝状腐食である。溝状腐食の事例解 析については既に報告した. 溝状腐食を生じた配管は しばしば孔食を伴って抏り，本報では孔食を生じてい るものを兄らび電縫部以外に生じている孔食を解析の 対象とした. 使用年数は 6 20年であり，管のサイズ は 25〜200Aにわたっている。これらの事例は測定時 には統計的な取り扱いを必ずしも意識していないので, データ数や測定サンプルの大きさがそろっていない． 同様に，極值統計を意識していないので，孔食深さの 最大值分布ではなく母分布を対象として論議する. 取 り扱った16件のうち孔食により貫通孔を生じたるのは 少なく, ボイラ補給水配管（使用 4 年） 1 件, 給水管 （使用 6 年拈よび 16 年） 2 件拈よび温水配管（使用 6 年および 20 年） 2 件の計 5 件である.このらち 3 件は 配管継ぎ手のねじ部で生じていた。

Fig. 1 亿配管内面に生じた孔食の外観を示す. Fig. 1 (a)の例は温水配管に 20 年使用した $50 \mathrm{~A}$ の管であり, ねじ部で貫通孔を生じている. Fig. 1 (b)の例は冷却循

$\dagger$ 原稿受理 昭和61年3月3日。 Received Mar.3, 1986

* 正会 員 日本剑管(株)中央研究所 川崎市川崎区南渡田, Technical Research Center, Nippon Kokan K.K., Kawasaki-ku, Kawasaki

** 日本鋼管(株)中央研究所 川崎市川崎区南渡田, Technical Research Center, Nippon Kokan K. K., Kawasaki-ku, Kawasaki 
Table I. List of pipes analysed.

\begin{tabular}{|c|c|c|c|c|c|}
\hline $\begin{array}{c}\text { Sam- } \\
\text { ple } \\
\text { No. }\end{array}$ & $\begin{array}{l}\text { Dia- } \\
\text { meter }\end{array}$ & $\begin{array}{l}\text { Len- } \\
\text { gth }\end{array}$ & $\begin{array}{c}\text { Dura- } \\
\text { tion }\end{array}$ & Environment & Note \\
\hline$A-1$ & $32 \mathrm{~A}$ & \begin{tabular}{|c|}
$\mathrm{cm}$ \\
17.5
\end{tabular} & $\begin{array}{l}\text { year } \\
17\end{array}$ & Hot water & Pitting \\
\hline$A-2$ & $60 \mathrm{~A}$ & 17.0 & 17 & Hot water & Pitting \\
\hline B-1 & $150 \mathrm{~A}$ & 60.0 & 20 & Potable water & Pitting \\
\hline B-4 & $50 \mathrm{~A}$ & 50.0 & 20 & Hot watwr & Pitting \\
\hline B-8 & $50 \mathrm{~A}$ & 50.0 & 20 & Hot water & Pitting \\
\hline$C-1$ & $50 \mathrm{~A}$ & 49.0 & 20 & Hot water return & Pitting \\
\hline $\mathrm{C}-2$ & $100 \mathrm{~A}$ & 49.0 & 20 & Potable water & Pitting \\
\hline$c-3$ & $100 \mathrm{~A}$ & 49.0 & 20 & Potable water & Pitting \\
\hline $\mathrm{D}-1$ & $50 \mathrm{~A}$ & 20.0 & 4 & Boiler feed & Pitting \\
\hline $\mathrm{E}-1$ & $80 \mathrm{~A}$ & 45.0 & 8 & Recycled water & Grooving \\
\hline $\mathrm{E}-3$ & $50 \mathrm{~A}$ & 15.0 & 8 & Recycled water & Grooving \\
\hline $\mathrm{F}-1$ & $200 \mathrm{~A}$ & 20.0 & 7 & Recycled water & Grooving \\
\hline$F-2$ & $200 \mathrm{~A}$ & 20.0 & 7 & Recycled water & Grooving \\
\hline $\mathrm{F}-3$ & $200 \mathrm{~A}$ & 20.0 & 7 & Recycled water & Grooving \\
\hline$F-4$ & $80 \mathrm{~A}$ & 20.0 & 7 & Recycled water & Grooving \\
\hline G-1 & $50 \mathrm{~A}$ & 35.0 & 17 & Potable water & Pitting \\
\hline G-2 & $50 \mathrm{~A}$ & 18.0 & 17 & Potable water & Pitting \\
\hline $\mathrm{G}-3$ & $40 \mathrm{~A}$ & 25.0 & 17 & Potable water & Pitting \\
\hline G-4 & $20 \mathrm{~A}$ & 28.0 & 17 & Potable water & Pitting \\
\hline$G-5$ & $25 \mathrm{~A}$ & 13.0 & 17 & Potable water & Pitting \\
\hline $\mathrm{H}-1$ & $150 \mathrm{~A}$ & 3.0 & 6 & Potable water & Pitting \\
\hline $\mathrm{I}-1$ & $80 \mathrm{~A}$ & 30.0 & 5 & Potable water & Grooving \\
\hline $\mathrm{J}-1$ & $100 \mathrm{~A}$ & 20.0 & 5 & Recycled water & Grooving \\
\hline $\mathrm{K}-1$ & $125 \mathrm{~A}$ & 50.0 & 5 & Recycled water & Grooving \\
\hline $\mathrm{L}-1$ & $100 \mathrm{~A}$ & 50.0 & 3 & Recycled water & Pitting \\
\hline$M-1$ & $80 \mathrm{~A}$ & 40.0 & 3 & Recycled water & Grooving \\
\hline $\mathrm{N}-1$ & $125 \mathrm{~A}$ & 50.0 & 16 & le water & Pitting \\
\hline $0-1$ & $100 \mathrm{~A}$ & 50.0 & 9 & Potable water & Grooving \\
\hline $\mathrm{P}-1$ & $100 \mathrm{~A}$ & 40.0 & 6 & Hot water & Pitting \\
\hline $\mathrm{P}-2$ & $65 \mathrm{~A}$ & 30.0 & 6 & Hot water & Pitting \\
\hline $\mathrm{P}-3$ & $50 \mathrm{~A}$ & 35.0 & 6 & Hot water & Pitting \\
\hline P-4 & $32 \mathrm{~A}$ & 28.0 & 6 & Hot water & Pitting \\
\hline
\end{tabular}

環水配管に 3 年使用した例である。孔食の発生は軽微 であり，実用上は溝状腐食の方が重要である。

孔食深さの測定はデプスゲージで行い，通常の作業 では任意に10〜20個の孔食を選び測定する方法でデー タを採取した，この方法では統阡的な片寄りが生じる 可能性があるため, 分布の形状やパラィータの推定に は20点以上の測定点があるものを使用した.

Fig. 2 にサンプルK-1の孔食深さのヒストグラムを

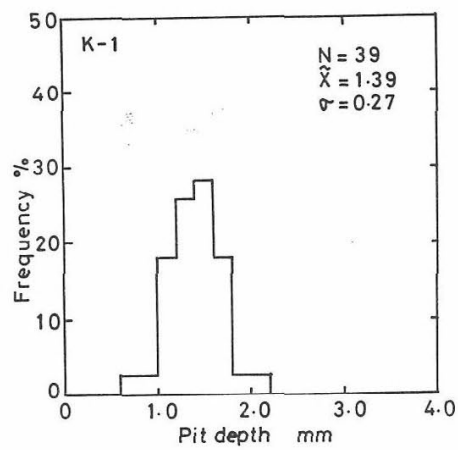

Fig. 2. Distribution of pit depth observed in pipe $\mathrm{K}-1$.

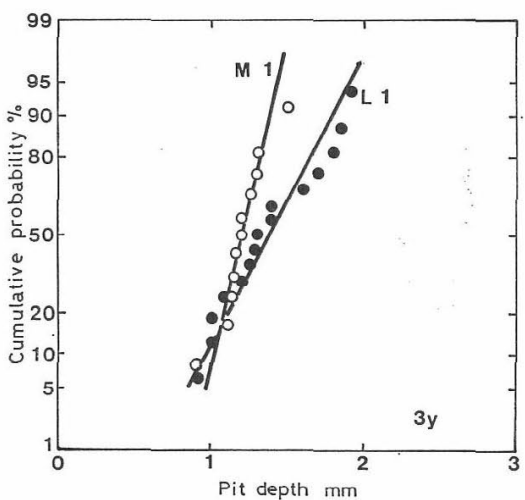

Fig. 3. Distribution of pit depth on normal probability paper observed in pipes used for 3 years.

示す。この例では正規分布に近い形の分布示してい る. 使用年数 3 年の事例 2 件の孔食深さの分布の正規 確率紙プロットをFig. 3 に示す．いずれの例も正規 確率紙上で直線になり，正規分布によく当てはめられ ることが分る. 平均值は両者共に余り差はないが，標 準偏差はサンプルL-1 の方が大きい. 使用 17 年の例 をFig. 4 に示す。，いずれも正規分布を当てはめるこ とができる、G-1〜5 に見られるように，同じ系統の

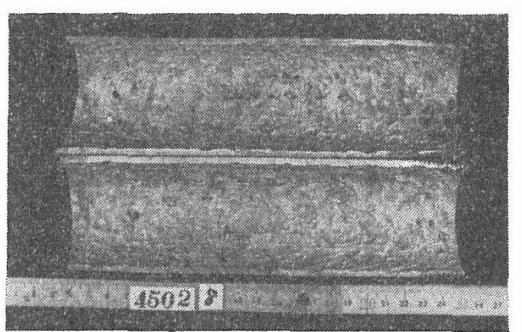

B-8
$50 \mathrm{~A}$

Hot water $20 y$

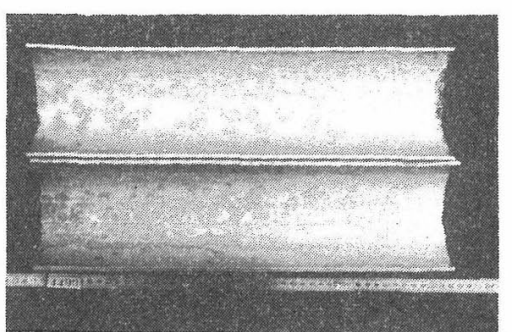

$\mathrm{L}-1$

$100 \mathrm{~A}$

Recycled water

$3 y$

(a) B-8 Hot water 20 years

(b) L-1 Recycled water 3 years

Fig. 1. Appearance of inner surface of pipes. 


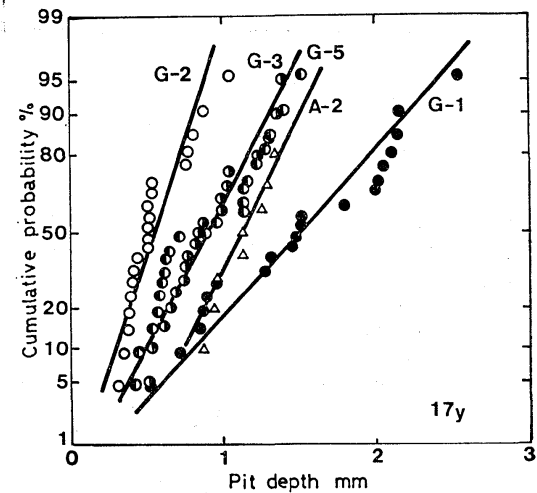

Fig. 4. Distribution of pit depth on mormal probability paper observed in pipes used for 17 years.

装置であっても孔食深さの分布に差がある。これは使 用環境が孔食の発生成長に大きく影響するためと考兄 られる。

他の測定結果もデータを正規分布で近似することが 可能であったので, 以後孔食深さの分布は正規分布に 当てはめることとする.

\section{3 分布パラメータの時間依存性}

Table II に各サンプルの孔食深さのデータを正規

Table II. Stastical parameters and mean penetration rate of pit in the pipes.

\begin{tabular}{|c|c|c|c|c|c|c|c|}
\hline $\begin{array}{c}\text { Sample } \\
\text { No. }\end{array}$ & $m(\mathrm{~mm})$ & $\sigma(\mathrm{mm})$ & $\begin{array}{c}m+3 \sigma \\
(\mathrm{mm})\end{array}$ & $\left(\begin{array}{c}v \\
(\mathrm{~mm} / \mathrm{y})\end{array}\right.$ & $n$ & $\begin{array}{l}\text { Wall } \\
\text { ness }\end{array}$ & $\begin{array}{l}\text { Thick- } \\
(\mathrm{mm})\end{array}$ \\
\hline$A-1$ & 1.59 & 0.49 & 3.06 & 0.09 & 19 & 3.50 & \\
\hline$A-2$ & 1.14 & 0.17 & 1.65 & 0.07 & 9 & 4.20 & \\
\hline B-1 & 0.60 & 0.13 & 0.99 & 0.03 & 14 & 5.00 & \\
\hline B-4 & 0.93 & 0.23 & 1.62 & 0.05 & 13 & 3.80 & \\
\hline B- 8 & 1.48 & 0.26 & 2.26 & 0.07 & 19 & 3.80 & Failed \\
\hline $\mathrm{C}-1$ & 0.65 & 0.16 & 1.10 & 0.03 & 20 & 3.80 & \\
\hline$C-2$ & 1.26 & 0.20 & 1.86 & 0.06 & 20 & 4.50 & \\
\hline$C-3$ & 1.63 & 0.26 & 2.41 & 0.08 & 39 & 4.50 & \\
\hline D-1 & 1.85 & 0.69 & 3.92 & 0.46 & 20 & 3.80 & Failed \\
\hline E-1 & 1.56 & 0.45 & 2.91 & 0.20 & 19 & 4.20 & \\
\hline$E-2$ & 0.27 & 0.09 & 0.54 & 0.03 & 5 & 3.80 & \\
\hline$E-3$ & 0.46 & 0.11 & 0.79 & 0.06 & 10 & 3.80 & \\
\hline$F-1$ & 1.54 & 0.25 & 2.29 & 0.29 & 10 & 5.80 & \\
\hline$F-2$ & 1.37 & 0.22 & 2.02 & 0.20 & 10 & 5.80 & \\
\hline$F-3$ & 1.50 & 0.17 & 2.01 & 0.21 & 10 & 5.80 & \\
\hline$F-4$ & 1.81 & 0.35 & 2.86 & 0.26 & 10 & 3.80 & \\
\hline $\mathrm{G}-1$ & 1.51 & 0.55 & 3.16 & 0.09 & 20 & 3.80 & \\
\hline G-2 & 0.55 & 0.19 & 1.12 & 0.03 & 20 & 3.80 & \\
\hline G-5 & 0.91 & 0.26 & 1.69 & 0.05 & 19 & 2.80 & \\
\hline $\mathrm{H}-1$ & 0.97 & 0.56 & 2.65 & 0.16 & 8 & 5.00 & Failed \\
\hline$I-1$ & 1.25 & 0.20 & 1.85 & 0.25 & 22 & 4.20 & \\
\hline$J-1$ & 1.46 & 0.49 & 2.93 & 0.29 & 20 & 4.50 & \\
\hline $\mathrm{K}-1$ & 1.39 & 0.27 & 2.20 & 0.28 & 39 & 4.50 & \\
\hline $\mathrm{L}-1$ & 1.38 & 0.31 & 2.31 & 0.46 & 15 & 4.50 & \\
\hline $\mathrm{M}-1$ & 1.20 & 0.14 & 1.62 & 0.40 & 11 & 4.20 & \\
\hline $\mathrm{N}-1$ & 2.04 & 0.79 & 4.41 & 0.13 & 20 & 4.50 & Failed \\
\hline $0-1$ & 2.24 & 0.14 & 2.66 & 0.25 & 59 & 4.50 & \\
\hline$P-1$ & 2.10 & 0.54 & 3.72 & 0.35 & 10 & 4.50 & Failed \\
\hline$P-2$ & 0.82 & 0.23 & 1.51 & 0.14 & 10 & 4.20 & \\
\hline $\mathrm{P}-3$ & 1.90 & 0.28 & 2.74 & 0.32 & 10 & 3.80 & \\
\hline $\mathrm{P}-4$ & 1.02 & 0.29 & 1.89 & 0.17 & 10 & 3.5 & \\
\hline
\end{tabular}

分布として扱ったときの平均值 $m$ と標準偏差 $\sigma$ の值を 示す. 正規分布の $99.9 \%$ 点に対応する孔食深さの推定 值としての $m+3 \sigma$ の值，打よび平均值 $m$ を使用年数 で割って求めた孔食の平均進行速度 $v$ を併せて示す. 孔食の平均進行速度は最も小さいもので $0.03 \mathrm{~mm} / \mathrm{y}$, 最大で $0.46 \mathrm{~mm} / \mathrm{y}$ であった. $m+3 \sigma$ の值が配管肉 厚に対して相対的に大きな場合に貫通孔が発生してい る. $m, \sigma$ などのパラメータの中では $m+3 \sigma$ が孔食 による事故を予測する指標となる。これは $m+3 \sigma$ が 最大孔食深さの近似值を与兄るためと思われる. 温水 配管の孔食の平均進行速度は温度の低い場合と比べて 必ずしも大きくない。

孔食深さの平均值と使用期間との関係を Fig. 5 に 示す. 孔食深さの平均值と使用期間との間には相関関 係が認められない。るた貫通孔を生じているサンプル の孔食深さの平均值は必ずしも大きくない.

Fig. 6 飞使用期間と孔食深さの標準偏差々の関係を 示す。平均値と同椂に使用時間との相関は認められな

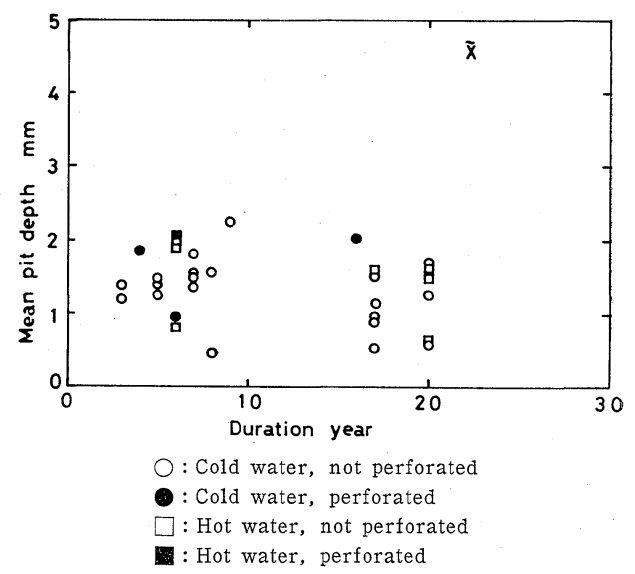

Fig. 5. Relationship between mean pit depth and duration of use.

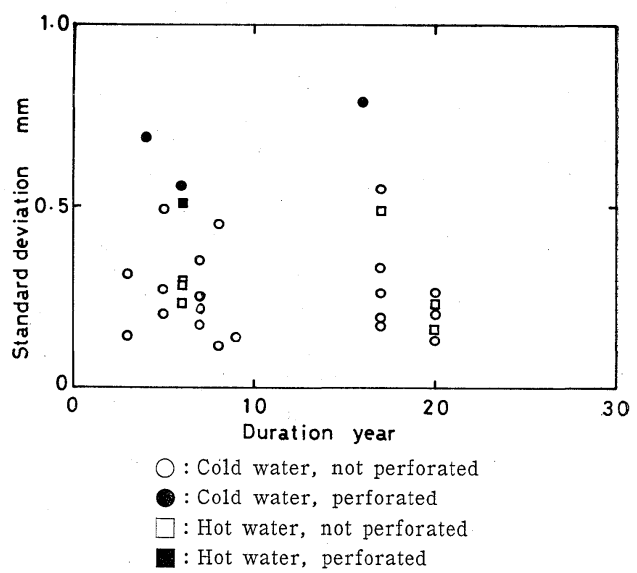

Fig. 6. Relationship between standard deviation of pit depth and duration of use. 
い.乙かし，貫通孔を生じているサンプルは標準偏差 の大きなるのであり, 平均値の大小よりは標準偏差の 大小の方が事故の発生飞密接な関係があることが分る.

以上に示したように, 事例の解析からは炭素鋼に生 じる孔食の進行速度の速度則を求めることはできなか った。これは，実使用条件では環境の差が大きく，独 立した配管内に生じた孔食深さを測定して整理しても 求めたパラメータが時間に依存したものにならないた めである。

Fig. 7 亿標準偏差と平均値の相関を示す. 平均値の 大きなるのほど標準偏差が大きくなる傾向がある。こ 孔は腐食が進行するにしたがって孔食深さの平均值が 增大すると共汇, 孔食の深いものの裾野が広がり標準 偏差が大きくなることを示している. 32例中28例では 標準偏差 $\sigma$ は $0.4 m<\sigma<0.4(m-1)$ の範囲に有る.

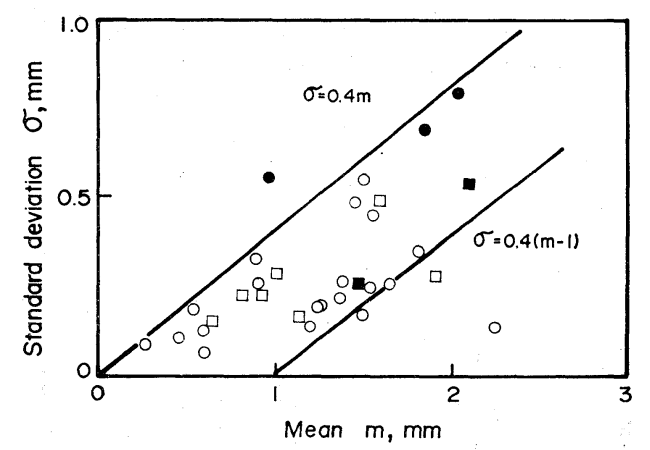

$O$ : Cold water, not perforated

- Cold water, perforated

$\square$ : Hot water, not perforated

. Hot water, perforated

Fig. 7. Relationship between mean pith depth and standard deviation of pit depth.

\section{4 ループテストによる結果}

淡水配管内面に生じるさびこぶ下の孔食の成長速度 の速度則を事例から求めることができないため,ルー プテストを実施した. 冷却循環水配管に全長 $5 \mathrm{~m}$ の $100 \mathrm{~A}$ の試験管を取り付けて $1 〜 3$ 年通水試験したサ ンプルの内面に生じた孔食深さの 分布を Fig. 8 に示 す. 測定区画は全長 $25.0 \mathrm{~cm}$ の $100 \mathrm{~A}$ の鋼管の内面で ある. 試験時間が長くなると分布が全体的に深い万へ 移動することが分る. この場合, 平均值が時間と共に 增加しているのに対し，標準偏差はむしろ減少してい る.これは事例解析の結果とは一致しない.

Fig. 9 亿最大孔食深さの極值確率プロットを示す. 最大孔食深さの分布を求めるために測定単位区画の大 きさを $12.5 \mathrm{~cm}$ の長さの管内面とし，14区画測定し た. 1 年試験したものに生じた孔食の深さの分布は極 值分布によく一致している. 一方 3 年試験したものは 極值確率紙上で折れ曲った直線となり，分布関数の值

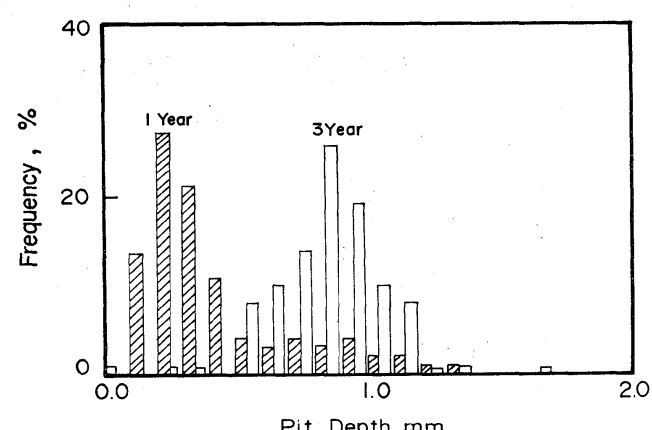

Pit Depth, $\mathrm{mm}$

Fig. 8. Distribution of pit depth observed in pipes tested for 1 and 3 years.

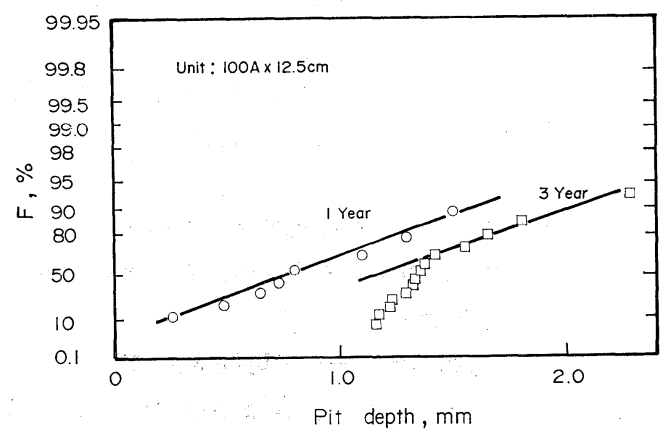

Fig. 9. Maximum pit depth on extreme probability paper observed in pipes tested for 1 and 3 years.

の大きな領域では 1 年試験したものとほぼ平行な直線 上にあるが，分布関数の值の小さな領域ではこれより 傾きの大きな直線上にある. 測定の単位区画を変更し ても分布の形状が㴗とんど変らないことから考光ると， この原因はサンプリング方法などの統計的な扱い方に よるものではなく，わずか $5 \mathrm{~m}$ のサンプル中にも腐食 のし方が違ら部分が存在して異なる分布に従らデータ が混在しているためと思われる. 貫通孔が生じるかぞ らかを議論するとき問題となるのは分布関数の値の大 きな部分であるから， $F>0.8$ 以上の部分の直線で比 較すると位置パラメータ入性用年数が長くなると大 きくなるがスケールパラメータいは変化していない。 これは，石川らが時間と共に $\alpha$ の值が大きくなるとす る報告とは異なっている. 本田らのデータでは $\alpha の$ 值 の時間依存性は明確ではない， $\alpha$ の時間による変化は $\lambda$ の変化よりも貫通孔が生じる確率に与える影響が大 きく, 重要な問題である. $\alpha$ が時間と共増加すると 貫通する確率も時間と共に急激に増加する。.今後検討 すべき課題である.

\section{5 考察}

淡水配管の内面に生じたさびこぶ下の孔食の深さの 分布が正規分布に従うので, 孔食深さの最大值の推定 に二重指数分布を利用した極地統計を利用することが 
可能である. しかし，正規分布から二重指数分布への 漸近は遅いことが知られて和り，単位区画の大きさに は注意をする必要がある.

孔食深さの分布のパラメータの内で事故が生じるか どらかに最も影響を与えるのは, 平均值 $m$ よりも標準 偏差。である。これは事例からも明らかであるが，孔 食深さがある分布にしたがっているとき，貫通孔を生 じる確率 $F$ は次のように与えられる.

$$
F=\operatorname{Pr}\left(x>x_{c r}\right)
$$

このとき $x_{c r}$ は限界の肉厚である. この様子を Fig. 10亿示す. 平均值が同じでも標準偏差 $\sigma$ の大さい方が 貫通孔を生じる確率が高くなる. 同様のことが極值分 布のスケールパラメータについても言える.

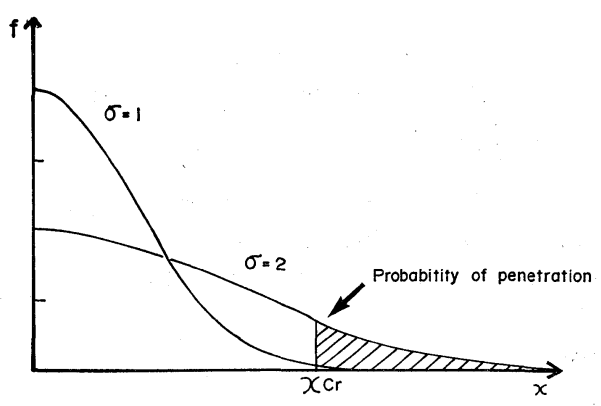

Fig. 10. Effect of standard deviation on the probability of penetration.

母分布の標準偏差の $\sigma$ 増加は, 最大孔食深さの極值 分布の $\alpha$ の值を大きくする. 事例解析から明らかとな った孔食深さの平均值が増加すると標準偏差が増加す る関係は, 石川らによって示された孔食の極值分布の $\alpha$ が時間と共に増加すると言う結論を間接的に支持す るものである. しかし, 制御された環境でのループテ ストの結果からはこの関係は確認されなかった. 上に も述べたように， $\alpha$ の值は事故の発生の確率に重要な
役割をもっているので $\alpha$ の時間依存性については今後 も十分に検討されるべきである.

最大孔食深さを推定する方法はいくつか考えられる. 孔食深さの母分布を求めて $m+3 \sigma$ の值を取るのもひ とつの方法である. 孔食の発生密度などの情報があれ ば，正規分布を利用して定量的な推定を行うことも不 可能ではない. 似た考方方として Champion は, Perforation factor として $m+2 \sigma$ を提案している.

しかし, 測定に要する労力と情報の量を比較すると賢 明な方法とは言い難い，極值統計による万法は比較的 簡単に定量的な推定が行える利点がある。しかし，十 分な大きさのサンプルが得られない場合などはここに 示したような方法で半定量的な推定を行らことは意味 のあることと思われる。

本報では孔食の進行速度の速度則を決定することは でさなかった。 また，たとえ速度則が決定されたとし てもとの誤差はかなり大きなものとなると思われる。

したがって，ある時点に括ける測定データだけで装置 の寿命を予測することは, 現時点ではかなり困難なこ とといわざるを得ない，今後この種のデータを積み上 げて行くことが重要であると考えられる.

\section{参 考 文 献}

1) 柴田俊夫, 岡本勝群, 防食技術, 30, 404 (1981).

2）井上圭典, 石油技術協会誌，47，419 (1982).

3）石川雄一, 尾崎敏範, 保坂信義, 西田. 修, 防食技術, 29, 502 (1980).

4) 本田正春, 酒井潤一, 松島 祳, 第 41 回腐食防食シンポ ジウム資料，p. 37 (1982) 腐食防食協会.

5）正村克身，松島＂㱟，防食技術，31，332 (1982).

6）山本一雄, 第 58 回腐食防食シンポジゥム資料, p. 14 (1984) 腐食防食協会.

7) Champion, J. Inst. Metals., 69, 495 (1943). 